\title{
Validation of spectral continuity between PROBA-V and SPOT-VEGETATION global daily datasets
}

\author{
W. Dierckx ${ }^{\text {a, } *, \text { E. Swinnen }}{ }^{\text {a }}$ P. Kempeneers ${ }^{\text {a }}$ \\ ${ }^{a}$ Flemish Institute for Technological Research (VITO), Remote Sensing Unit, Boeretang 200, 2400 Mol, Belgium - \\ Wouter.dierckx@vito.be
}

KEY WORDS: PROBA-V, Global, Daily, SPOT-VEGETATION, NDVI, Inter-calibration

\begin{abstract}
:
Spectral consistency with SPOT-VEGETATION is an important mission objective for PROBA-V, in particular for its $1 \mathrm{~km}$ products. This must allow service providers such as the Copernicus Global Land Service to extend the 16-year long timeseries of SPOTVEGETATION global $1 \mathrm{~km}$ data with similar PROBA-V products. To evaluate the extent of spectral consistency, an evaluation of spectral response differences is performed by applying the spectral response of PROBA-V and SPOT-VEGETATION 2 to a spectral library of representative global land cover conditions. Datasets for surface reflectance values and Normalized Difference Vegetation Index (NDVI) are thus established for both missions. Through linear regression between the two datasets, spectral correction functions are defined, which can be used to improve the spectral consistency between PROBA-V and SPOT-VEGETATION products. The correspondence between PROBA-V and SPOT-VEGETATION products is then evaluated for the overlapping period when products from both missions were available. The effect of the spectral correction functions is assessed by comparing the correspondence obtained with and without this spectral correction applied. For the NDVI product, an additional offset correction is defined based on a limited sample of the overlapping period. The final spectral correction functions are then evaluated over the full overlapping period between PROBA-V and SPOT-VEGETATION. Discrepancies are observed which indicate a temporal behavior with respect to the correspondence of the mission products. Such temporal behavior can't be explained by spectral response differences, and therefore other causes are investigated.
\end{abstract}

\section{INTRODUCTION}

PROBA-V is the direct successor mission to SPOTVEGETATION, which provided near-daily global coverage of vegetation at $1 \mathrm{~km}$ resolution from 1 May 1998 up to 31 May 2014. As one of its main objectives, PROBA-V provides continuity of the SPOT-VEGETATION time series. To achieve this, its mission definition fulfills the same near-daily global coverage and provides products at $1 \mathrm{~km}$ and $300 \mathrm{~m}$ resolution in the same spectral bands: Blue, Red, NIR, SWIR (Dierckx et al., 2014). PROBA-V is currently operational and has been operational since 15 October 2013, thereby ensuring an overlapping period with SPOT-VEGETATION products of 7.5 months.

Although the PROBA-V sensor was spectrally defined as similar as possible to SPOT-VEGETATION, there are nevertheless differences to cope with, related to differences in the camera system and geometry, but also associated with spectral characteristics (Sterckx et al., 2014). In this study, these aspects have been assessed in view of the extension of the NDVI time series of SPOT-VEGETATION with NDVI time series from PROBA-V $1 \mathrm{~km}$ products.

A consistent transfer between these time series is an important requirement from the Copernicus Global Land Service (CGLS), which operates a multi-purpose service component of biogeophysical products at global scale. For time-series analysis, the application of correction functions that account for spectral response differences between sensors significantly improves the consistency. Such correction functions have been derived from a spectral library thar originates from spectral measurements or simulations (Trishchenko, 2002; Steven et al., 2003; Gonsamo et al., 2013). This approach has been used to derive spectral response correction functions that must be applied to PROBA$\mathrm{V}$ to obtain data similar to SPOT-VEGETATION. This spectral correction has then been evaluated by comparing paired tendaily $1 \mathrm{~km}$ top-of-canopy composites from both missions.

\section{METHOD}

\subsection{Derivation of spectral correction functions}

Global representative vegetation spectra are generated using the coupled PROSPECT-5 and 4SAIL models, i.e. PRO4SAIL from (Jacquemoud et al., 2009). The parameterization of the different input variables is defined based on similar simulations performed by (Baret et al., 2007, Gonsamo \& Chen, 2013, Weiss et al., 2010), and specified in Table 1. The sampling scheme is according to a full orthogonal experimental plan (Bacour et al., 2002), where variables are divided in equally spaced classes and all combinations of classes are sampled once. This process allows accounting for all the interactions, while having the range of variation for each variable densely and near randomly populated.

20736 simulations are thus generated using PROSPECT and SAIL models with these specifications. The actual distribution of the variables is shown in Figure 1. 


\begin{tabular}{|c|c|c|c|c|c|c|c|c|}
\hline & $\begin{array}{c}\text { Input } \\
\text { variable }\end{array}$ & Unit & Distribution law & LB & UB & Mode & Std & $\begin{array}{l}\text { No of } \\
\text { classes }\end{array}$ \\
\hline Chlorophyll content & $\mathrm{Cab}$ & $\mu \mathrm{g} . \mathrm{cm}^{-2}$ & Trunc. Gauss. & $\begin{array}{c}15 \\
5\end{array}$ & $\begin{array}{c}100 \\
5\end{array}$ & 50 & 30 & 3 \\
\hline & Car & & & & 5 & & & \\
\hline $\begin{array}{l}\text { Brown pigment } \\
\text { content }\end{array}$ & Cbrown & - & Trunc. Gauss. & 0 & 1.5 & 0 & 0.6 & 2 \\
\hline $\begin{array}{l}\text { Equivalent water } \\
\text { thickness }\end{array}$ & $\mathrm{Cw}$ & g.cm-2 & & 0.008 & 0.08 & 0.03 & 0.03 & 2 \\
\hline $\begin{array}{l}\text { Leaf mass per unit } \\
\text { leaf area }\end{array}$ & $\mathrm{Cm}$ & g.cm-2 & Trunc. Gauss. & 0.002 & 0.02 & 0.0075 & 0.0075 & 2 \\
\hline Structure coefficient & Ns & - & Trunc. Gauss. & 1 & 4.5 & 1.5 & 1 & 2 \\
\hline $\begin{array}{l}\text { Average leaf } \\
\text { inclination }\end{array}$ & Angl & degrees & Trunc. Gauss. & 30 & 85 & 60 & 20 & 3 \\
\hline Leaf area index & LAI & - & Uniform & 0 & 8 & - & - & 4 \\
\hline Hot spot & Hspot & - & Trunc. Gauss. & 0.001 & 1 & 0.1 & 0.3 & 2 \\
\hline Sun zenith angle & Tts & Degrees & Uniform & 0 & 90 & & & 3 \\
\hline $\begin{array}{l}\text { Observation zenith } \\
\text { angle }\end{array}$ & tto & Degrees & Uniform & 0 & 60 & & & 3 \\
\hline Relative azimuth & Psi & Degrees & 2x Gauss. & 50 & 230 & & & 2 \\
\hline Soil coefficient & psoil & - & Uniform & 0 & 1 & & & 2 \\
\hline $\begin{array}{l}\text { Diffuse/direct } \\
\text { radiation }\end{array}$ & skyl & $\%$ & Constant & 70 & 70 & & & \\
\hline
\end{tabular}

Table 1. Input specifications for PROSAIL

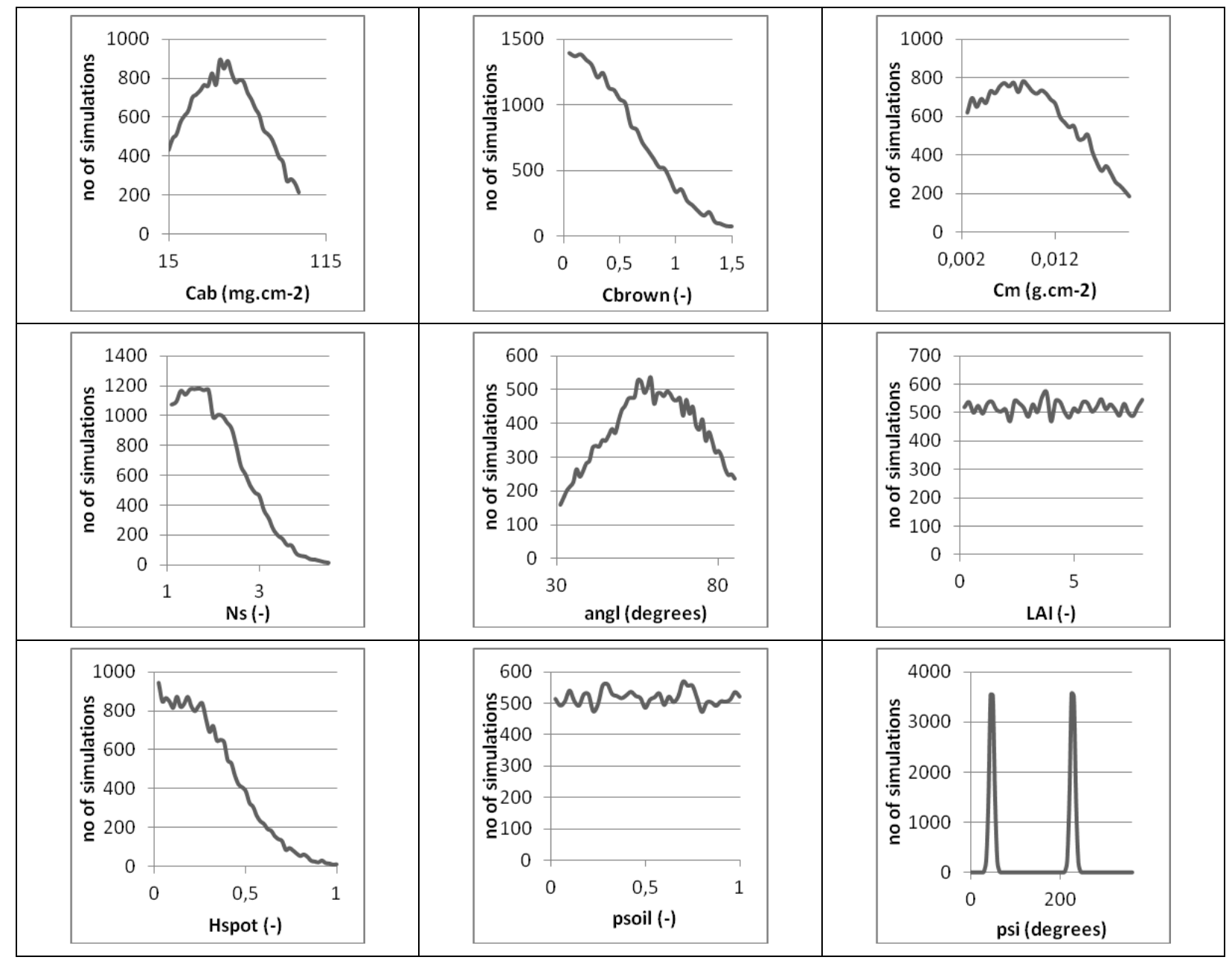

Figure 1. Histograms of the actual values used for the various input parameters of PROSPECT and SAIL to generate the simulated data set 
The spectra are upscaled to top-of-atmosphere spectral radiances using MODTRAN 5 (Berk et al., 2005) with the parameters listed in Table 2, and using a fixed and standard illumination and observation geometry $\left(\mathrm{TTs}=45^{\circ}, \mathrm{TTo}=0^{\circ}\right.$ and relative azimuth $=0^{\circ}$ ), commonly used to normalize satellite observations (Gonsamo et al., 2013).

\begin{tabular}{|l|l|l|l|}
\hline Input variable & Unit & Law & Values \\
\hline Water vapour & g.cm-2 & Regular & $1.5,5.0$ \\
Ozone & DU & Regular & $0.2,0.6$ \\
AOD at $550 \mathrm{~nm}$ & {$[]$.} & Regular & $0.2,0.5,0.7$ \\
Altitude & $\mathrm{Km}$ & Regular & 0,3 \\
Day of the year & {$[]$.} & Fixed & 137 \\
\hline
\end{tabular}

Table 2. Input specifications for MODTRAN 5

Top-of-atmosphere sensor radiance values are derived by convolution of the spectral radiances with the sensor spectral response functions of PROBA-V and SPOT-VEGETATION (Figure 2). From this, top-of-atmosphere reflectance values can be derived using

$$
\rho_{i}=\frac{\pi \cdot L_{i} \cdot d^{2}}{E_{\mathrm{i}} \cdot \cos (T T s)}
$$

where

$\rho_{i}=$ top-of-atmosphere reflectance

$L_{i}=$ top-of-atmosphere radiance

$E_{\mathrm{i}}=$ solar irradiance, from (Thuillier et al., 2003)

TTs $=$ solar zenith angle, set to $45^{\circ}$ for all cases

Band $\mathrm{i}=$ Blue, Red, NIR, SWIR

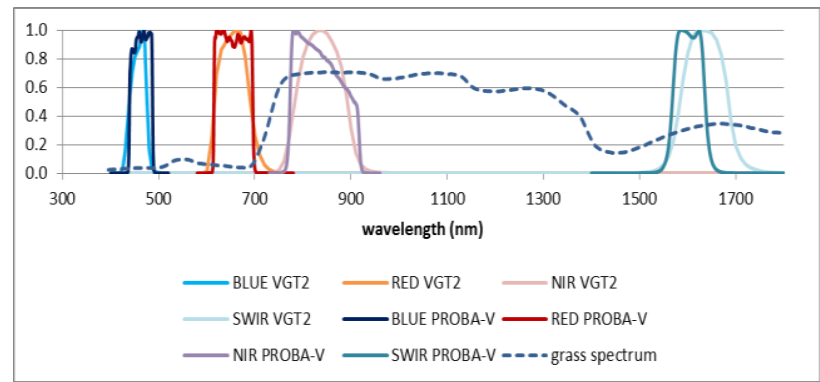

Figure 2. Spectral response functions of VGT2 and PROBA-V, superimposed with a spectrum of green grass

The top-of-atmosphere reflectance values can finally be transformed to top-of-canopy reflectance by downscaling with the same atmospheric variables just for upscaling the original spectra.

Spectral correction functions are derived through ordinary least squares regression (OLS) of the VGT2 and PROBA-V datasets, both for top-of-canopy reflectance and top-of-atmosphere reflectance, and this for all bands. The spectral correction function is of the form

$$
V G T 2_{\mathrm{i}}=\text { off } \mathrm{set}_{\mathrm{i}}+\text { slope }_{\mathrm{i}}-\text { ProbaV }_{\mathrm{i}}
$$

where

$$
\text { Band } \mathrm{i}=\text { Blue, Red, NIR, SWIR }
$$

The effectiveness of the linear regression is evaluated by calculating the agreement coefficient and the root-mean-square error (RMSE). All statistical measures are defined in the Appendix.

\subsection{Comparison of PROBA-V and VGT2}

An initial evaluation is made on a set of seven ten-daily top-ofcanopy composites of PROBA-V and VGT2 within the overlapping period: $01 / 01 / 2014$ to $01 / 03 / 2014$. The evaluation is based on a systematic spatial subsampling of global composites, whereby the center pixel of each zone of $21 \times 21$ pixels is selected. The global extent outlines a region from $180^{\circ} \mathrm{W}$ to $180^{\circ} \mathrm{E}, 75^{\circ} \mathrm{N}$ to $56^{\circ} \mathrm{S}$. Only pixels identified by both PROBA-V and VGT2 as clear and good observations are selected from the subsampled composites. To reduce the effects of differences in viewing geometry and orbital overpass, the following additional selection criteria were used:

1. Pixels are of the same day (this can be derived from the TIME data layer in the S10 Products)

2. View Zenith Angle $<30^{\circ}$ (for both PROBA-V and VGT2)

3. View Azimuth Angle difference $<25^{\circ}$ ( ie. $\left|V_{\text {VAAOBA-V }}-\mathrm{VAA}_{\mathrm{VGT} 2}\right|<25^{\circ}$ )

4. Solar Zenith Angle difference $<10^{\circ}$ (ie. $\mid S Z A_{\text {PROBA-V }}$ $-\mathrm{SZA}_{\mathrm{VGT} 2} \mid<10^{\circ}$ )

As such, the evaluation is based on a sample of approximately 7000 paired observations from these 7 paired composites.

Several statistical measures are calculated for this sample between PROBA-V (X) and VGT2(Y): geometric mean regression, the Mean Squared Difference (overall, unsystematic and systematic), and the Mean Bias Error (MBE). These measures are defined in the Appendix.

A final evaluation is made on the full overlapping period from $21 / 10 / 2013$ to $21 / 05 / 2014$, following the same methodology, and comparing the correspondence between PROBA-V and VGT2 datasets with and without the spectral correction applied.

\section{RESULTS}

\subsection{TOA spectral correction functions}

Figure 3 shows the linear regression results for the TOA reflectance datasets. Table 3 summarizes the resulting correction functions, and also provides values for the RMSE and the agreement coefficient. Differences are very small for Blue, Red and NIR bands, with an RMSE of 0.003, which is on the level of the surface reflectance resolution specification, and thus at the limits of the mission sensor's discrimination capability (Saint, 1995). For SWIR, a decrease of $2.1 \%$ in the slope from VGT2 to PROBA-V is found, which can be explained from the shift to lower wavelengths in the spectral response function (Figure 2). 
(a)

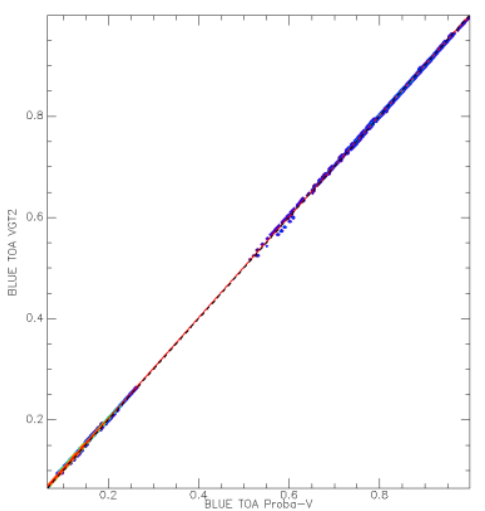

(b)

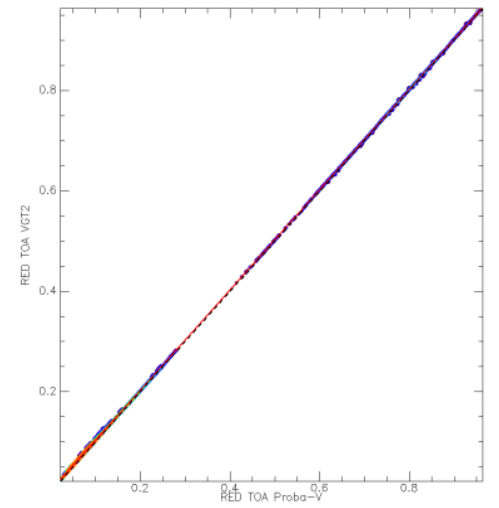

(c)

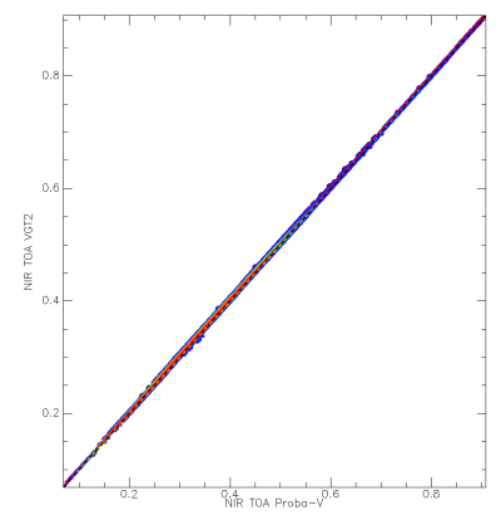

(d)

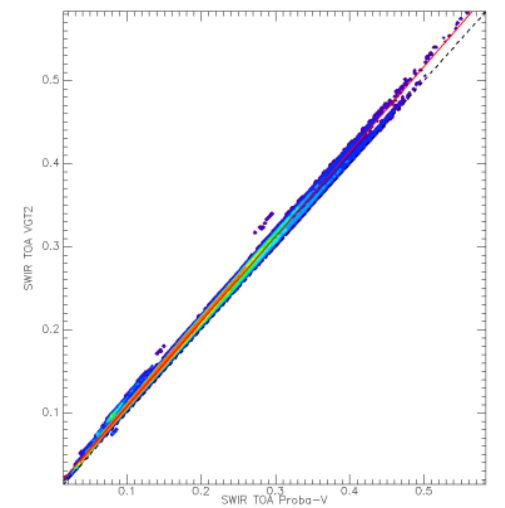

(e)

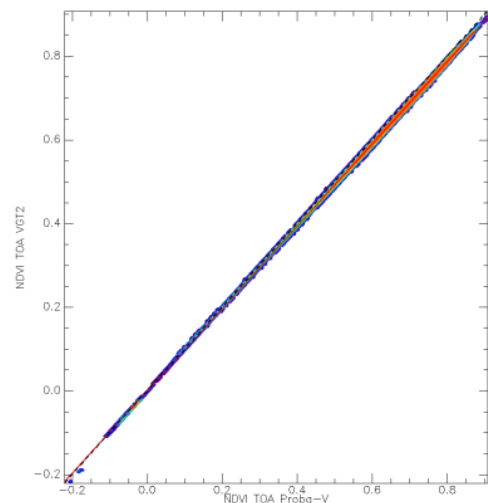

Figure 3. Scatterplots between simulated TOA reflectances of PROBA-V and VGT-2 for (a) Blue; (b) Red; (c) NIR; (d) SWIR; (e) NDVI

\begin{tabular}{|c|c|c|c|c|}
\hline & OLS offset & OLS slope & $\begin{array}{c}\text { agreement } \\
\text { coefficient }\end{array}$ & RMSE \\
\hline BLUE & 0.0034 & 0.9971 & 0.999 & 0.0032 \\
\hline RED & 0.0029 & 0.9983 & 0.999 & 0.0030 \\
\hline NIR & 0.0024 & 1.0005 & 0.999 & 0.0031 \\
\hline SWIR & 0.0062 & 1.0214 & 0.986 & 0.0100 \\
\hline NDVI & 0.0005 & 0.9843 & 0.997 & 0.0107 \\
\hline
\end{tabular}

Table 3. TOA spectral correction functions between PROBA-V and VGT2

For NDVI, an increase of $1.6 \%$ is found, which judging from the agreement coefficient appears to be systematic, indicating that a spectral correction function should be beneficial for the consistency of the NDVI products.

\subsection{TOC spectral correction}

Figure 4 shows the linear regression results for the TOA reflectance datasets. Table 4 summarizes the resulting correction functions, again with $\mathrm{AC}$ and RMSE values provided.

\begin{tabular}{|l|c|c|c|c|}
\hline & OLS offset & OLS slope & $\begin{array}{c}\text { agreement } \\
\text { coefficient }\end{array}$ & RMSE \\
\hline BLUE & 0.0015 & 1.0056 & 1.000 & 0.0020 \\
\hline RED & 0.0024 & 1.0019 & 0.999 & 0.0031 \\
\hline NIR & 0.0001 & 0.9980 & 1.000 & 0.0020 \\
\hline SWIR & 0.0021 & 0.9867 & 0.999 & 0.0039 \\
\hline NDVI & -0.0042 & 0.9859 & 0.999 & 0.0139 \\
\hline
\end{tabular}

Table 4. TOC spectral correction functions between PROBA-V and VGT2 
(a)

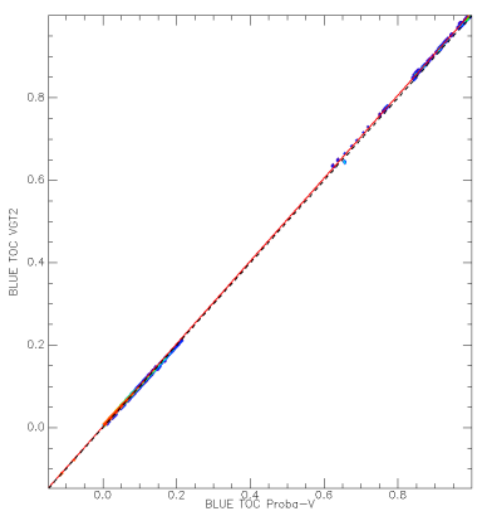

(b)

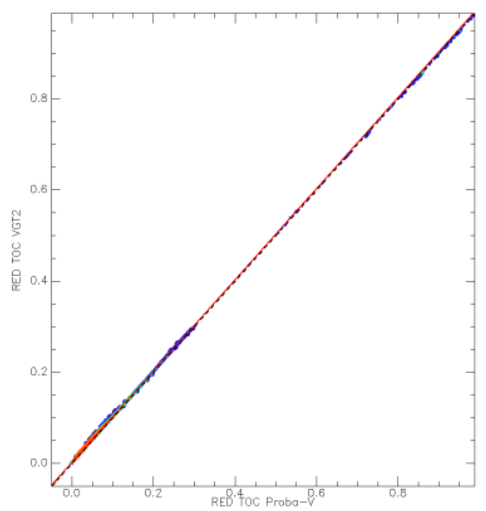

(c)

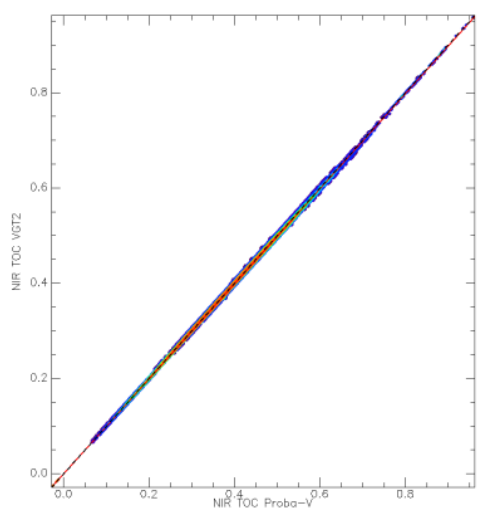

(d)

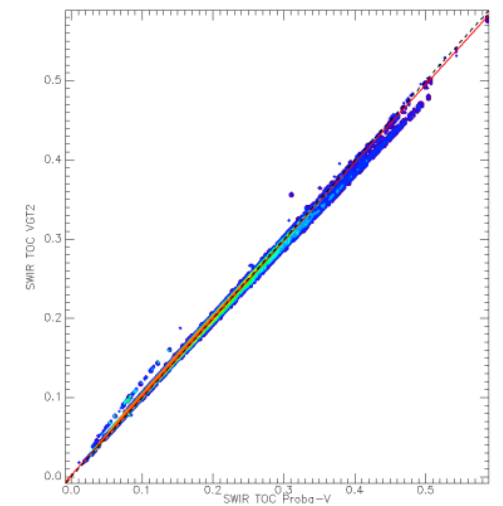

(e)

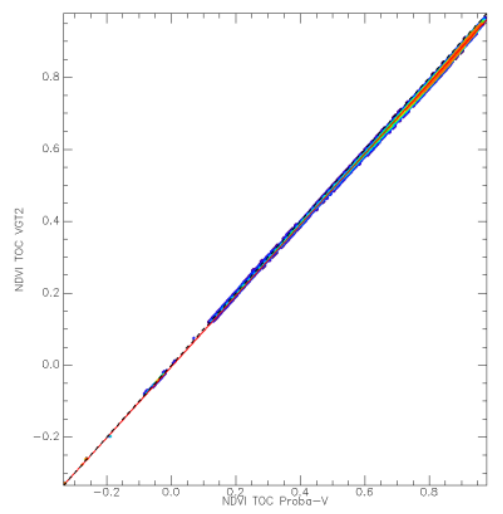

Figure 4. Scatterplots between simulated TOC reflectances of PROBA-V and VGT-2 for (a) Blue; (b) Red; (c) NIR; (d) SWIR; (e) NDVI

All results except the SWIR band results show comparable RMSE and agreement coefficients..For SWIR, the TOC correction shows better RMSE and agreement than the TOA correction. Interestingly, for all reflectance band results the slope correction values show the opposite trend from those found for the TOA datasets, particularly for the SWIR band. Only the NDVI results shows a similar trend in its TOA and TOC correction functions.

\subsection{Evaluation over the limited overlapping period}

Table 5 shows statistical measures comparing PROBA-V TOC composites against corresponding VGT2 TOC composites. Three sets of PROBA-V data are considered. The original set are PROBA-V composites without spectral correction. Set1 are PROBA-V composites with the TOC spectral correction functions from section 3.2 applied. As a residual offset was apparent after this correction, a Set 2 correction was defined which consists of the set 1 correction, with an additional offset correction based on the regression results from the Set1 dataset. The comparison for each of this sets is done for the Blue, Red, NIR and SWIR TOC reflectance products, as well as the TOC NDVI product.

The main result of the correction set 1 is indeed that the MBE is not reduced, even increased for some cases. This indicates that there is a residual offset effect present after spectral correction. It can be supposed that this offset must not attributed to spectral differences, but to other causes of discrepancies, which are not modeled by the spectral correction functions. For the SWIR and NDVI datasets, the application of the spectral correction functions has a beneficial effect, in the sense that the GM slope is closer to 1 . 


\begin{tabular}{|c|c|c|c|c|c|}
\hline Blue & $\begin{array}{l}\text { Gm } \\
\text { offset }\end{array}$ & $\begin{array}{l}\text { Gm } \\
\text { slope }\end{array}$ & $\mathrm{MPDu}$ & MPDs & $\mathrm{MBE}$ \\
\hline Orig & -0.010 & 1.011 & $1.9 \mathrm{E}-3$ & $9.2 \mathrm{E}-5$ & $9.6 \mathrm{E}-3$ \\
\hline Set 1 & -0.010 & 1.003 & $2.0 \mathrm{E}-3$ & $1.0 \mathrm{E}-4$ & $1.0 \mathrm{E}-2$ \\
\hline Set 2 & $2.9 \mathrm{E}-5$ & 1.003 & $2.0 \mathrm{E}-3$ & $9.9 \mathrm{E}-8$ & $-2.0 \mathrm{E}-4$ \\
\hline Red & $\begin{array}{l}\text { Gm } \\
\text { offset }\end{array}$ & $\begin{array}{l}\text { Gm } \\
\text { slope }\end{array}$ & MPDu & MPDs & MBE \\
\hline Orig & -0.008 & 0.999 & $2.1 \mathrm{E}-3$ & $6.0 \mathrm{E}-5$ & $7.8 \mathrm{E}-3$ \\
\hline Set 1 & -0.010 & 0.996 & $2.1 \mathrm{E}-3$ & $1.0 \mathrm{E}-4$ & $1.0 \mathrm{E}-2$ \\
\hline Set 2 & $-3.4 \mathrm{E}-5$ & 0.996 & $2.1 \mathrm{E}-3$ & $2.8 \mathrm{E}-7$ & $4.2 \mathrm{E}-4$ \\
\hline NIR & $\begin{array}{l}\text { Gm } \\
\text { offset }\end{array}$ & $\begin{array}{l}\text { Gm } \\
\text { slope }\end{array}$ & $\mathrm{MPDu}$ & MPDs & $\mathrm{MBE}$ \\
\hline Orig & -0.013 & 0.996 & $2.8 \mathrm{E}-3$ & $1.9 \mathrm{E}-4$ & $1.4 \mathrm{E}-2$ \\
\hline Set 1 & -0.013 & 0.997 & $2.8 \mathrm{E}-3$ & $1.8 \mathrm{E}-4$ & $1.3 \mathrm{E}-2$ \\
\hline Set 2 & $-3.3 \mathrm{E}-5$ & 0.997 & $2.8 \mathrm{E}-3$ & $3.5 \mathrm{E}-7$ & $5.6 \mathrm{E}-4$ \\
\hline SWIR & $\begin{array}{l}\text { Gm } \\
\text { offset }\end{array}$ & $\begin{array}{l}\text { Gm } \\
\text { slope }\end{array}$ & $\mathrm{MPDu}$ & MPDs & MBE \\
\hline Orig & 0.001 & 0.975 & $1.5 \mathrm{E}-3$ & $1.7 \mathrm{E}-5$ & $3.8 \mathrm{E}-3$ \\
\hline Set 1 & -0.001 & 0.988 & $1.5 \mathrm{E}-3$ & $9.7 \mathrm{E}-6$ & $3.0 \mathrm{E}-3$ \\
\hline Set 2 & $-8.5 \mathrm{E}-6$ & 0.988 & $1.5 \mathrm{E}-3$ & $6.0 \mathrm{E}-6$ & $2.3 \mathrm{E}-3$ \\
\hline NDVI & $\begin{array}{l}\text { Gm } \\
\text { offset }\end{array}$ & $\begin{array}{l}\mathrm{Gm} \\
\text { slope }\end{array}$ & MPDu & MPDs & MBE \\
\hline Orig & 0.017 & 0.978 & $3.4 \mathrm{E}-3$ & $9.1 \mathrm{E}-5$ & $-8.8 \mathrm{E}-3$ \\
\hline Set 1 & 0.023 & 0.990 & $3.4 \mathrm{E}-3$ & $3.9 \mathrm{E}-4$ & $-2.0 \mathrm{E}-2$ \\
\hline Set 2 & $2.3 \mathrm{E}-4$ & 0.990 & $3.4 \mathrm{E}-3$ & $1.4 \mathrm{E}-5$ & $3.3 \mathrm{E}-3$ \\
\hline
\end{tabular}

The effectiveness of the Set 1 and Set 2 corrections is evaluated over the full overlapping period as was done for the limited period (Table 6, Table 7).

\begin{tabular}{|c|c|c|c|c|c|}
\hline Blue & Gm offset & Gm slope & $\mathrm{MPDu}$ & MPDs & MBE \\
\hline \multirow{2}{*}{ Orig } & -0.007 & 0.924 & $6.1 \mathrm{E}-4$ & $1.8 \mathrm{E}-4$ & $1.2 \mathrm{E}-2$ \\
\hline & -0.010 & 1.011 & $1.9 \mathrm{E}-3$ & 9.2E-5 & $9.6 \mathrm{E}-3$ \\
\hline \multirow{2}{*}{ Set 1} & -0.008 & 0.912 & $5.7 \mathrm{E}-4$ & $2.3 \mathrm{E}-4$ & $1.4 \mathrm{E}-2$ \\
\hline & -0.010 & 1.003 & $2.0 \mathrm{E}-3$ & $1.0 \mathrm{E}-4$ & $1.0 \mathrm{E}-2$ \\
\hline Red & Gm offset & Gm slope & MPDu & MPDs & MBE \\
\hline \multirow{2}{*}{ Orig } & 0.001 & 0.912 & $6.1 \mathrm{E}-4$ & $1.5 \mathrm{E}-4$ & 8.7E-3 \\
\hline & -0.008 & 0.999 & $2.1 \mathrm{E}-3$ & $6.0 \mathrm{E}-5$ & $7.8 \mathrm{E}-3$ \\
\hline \multirow{2}{*}{ Set 1} & -0.001 & 0.909 & $5.6 \mathrm{E}-4$ & $2.1 \mathrm{E}-4$ & $1.2 \mathrm{E}-2$ \\
\hline & -0.010 & 0.996 & $2.1 \mathrm{E}-3$ & $1.0 \mathrm{E}-4$ & $1.0 \mathrm{E}-2$ \\
\hline NIR & Gm offset & Gm slope & MPDu & MPDs & MBE \\
\hline \multirow{2}{*}{ Orig } & -0.005 & 0.934 & $1.2 \mathrm{E}-3$ & 4.9E-4 & $2.1 \mathrm{E}-2$ \\
\hline & -0.013 & 0.996 & $2.8 \mathrm{E}-3$ & $1.9 \mathrm{E}-4$ & $1.4 \mathrm{E}-2$ \\
\hline \multirow{2}{*}{ Set 1} & -0.006 & 0.937 & $1.1 \mathrm{E}-3$ & $5.2 \mathrm{E}-4$ & $2.2 \mathrm{E}-2$ \\
\hline & -0.013 & 0.997 & $2.8 \mathrm{E}-3$ & $1.8 \mathrm{E}-4$ & $1.3 \mathrm{E}-2$ \\
\hline SWIR & Gm offset & Gm slope & MPDu & MPDs & MBE \\
\hline \multirow{2}{*}{ Orig } & 0.002 & 0.941 & 7.3E-4 & $1.4 \mathrm{E}-4$ & $9.8 \mathrm{E}-3$ \\
\hline & 0.001 & 0.975 & $1.5 \mathrm{E}-3$ & $1.7 \mathrm{E}-5$ & $3.8 \mathrm{E}-3$ \\
\hline \multirow{2}{*}{ Set 1} & -0.001 & 0.956 & $6.9 \mathrm{E}-4$ & $1.2 \mathrm{E}-4$ & $9.6 \mathrm{E}-3$ \\
\hline & -0.001 & 0.988 & $1.5 \mathrm{E}-3$ & $1.0 \mathrm{E}-5$ & $3.0 \mathrm{E}-3$ \\
\hline
\end{tabular}

Table 6. Statistical measures for the comparison of PROBA-V (X) and VGT2 (Y) TOC reflectance composites for the original PROBA-V data and the Set1 PROBA-V data

X) and VGT2 (Y) composites for the original PROBA-V data and for 2 sets of spectrally corrected PROBA-V data

The Gm offset was subsequently applied to the Set1 dataset, and evaluated as correction Set2. Set2 clearly shows reduction of the systematic error for all but the SWIR product, and thus a reduction of the MBE and MPDs. The remaining error is largely due to unsystematic difference (MPDu), which implies that remaining errors show variations over time, and such variations can not be improved by static spectral correction functions.

\subsection{Evaluation over the full overlapping period}

The additional offset introduced in correction Set 2 is derived from the regression results on the Set1 dataset. The cause of this offset could be attributed to other causes which include differences in illumination conditions and differences in observation geometry. For the reflectance products, the additional offset has not been applied in order to preserve the relationship between reflectances and the illumination and observation geometry. Thus, the additional offset has only been considered for the NDVI product.

\begin{tabular}{|l|r|r|c|l|l|}
\hline NDVI & Gm offset & Gm slope & \multicolumn{1}{l}{ MPDu } & MPDs & \multicolumn{1}{l}{ MBE } \\
\hline \multirow{2}{*}{ Orig } & 0.025 & 0.942 & $4.4 \mathrm{E}-3$ & $2.4 \mathrm{E}-4$ & $-4.0 \mathrm{E}-4$ \\
\cline { 2 - 6 } & 0.017 & 0.978 & $3.4 \mathrm{E}-3$ & $9.1 \mathrm{E}-5$ & $-8.8 \mathrm{E}-3$ \\
\hline \multirow{2}{*}{ Set 1} & 0.029 & 0.956 & $4.3 \mathrm{E}-3$ & $2.4 \mathrm{E}-4$ & $-1.0 \mathrm{E}-2$ \\
\cline { 2 - 6 } & 0.023 & 0.990 & $3.4 \mathrm{E}-3$ & $3.9 \mathrm{E}-4$ & $-2.0 \mathrm{E}-2$ \\
\hline \multirow{2}{*}{ Set 2} & 0.007 & 0.956 & $4.3 \mathrm{E}-3$ & $2.8 \mathrm{E}-4$ & $1.2 \mathrm{E}-2$ \\
\cline { 2 - 6 } & $2.0 \mathrm{E}-4$ & 0.990 & $3.4 \mathrm{E}-3$ & $1.4 \mathrm{E}-5$ & $3.3 \mathrm{E}-3$ \\
\hline
\end{tabular}

Table 7. Statistical measures for the comparison of PROBA-V

(X) and VGT2 (Y) TOC NDVI composites for the original PROBA-V data, Set1 and Set2 PROBA-V data

For Blue and Red datasets, the Set1 correction seems to be slightly degrading the relationship between PROBA-V and VGT2: MBE and MPDs are increased, and the GMslope is further from 1 when comparing the new Set1 results with the new Original PROBA-V results. For NIR and SWIR, there is a slight improvement of the similarity after spectral correction. The most striking result however is the lower value of 
GMslope, indicating a decrease in the spectral consistency of PROBA-V and VGT2.

For the NDVI Set1, similar trends are observed: a lower value of GM slope, and an increase of the MBE after correction. The offset correction of Set2 does seem to correct for the offset between the two datasets, but spectral consistency is not noticeably improved. This is clearly a different result from the limited overlapping period.

\subsection{Explanation of the difference}

The different results found between section 3.3 and 3.4 between indicate that a change has occurred in the correspondence between PROBA-V and VGT2, between the limited overlapping period in the 2 months of 2014, and the full overlapping period which contains data from October 2013 to May 2014. This temporal behavior is exposed by showing the histogram of differences between PROBA-V NDVI and VGT-2 NDVI, for each of the ten-day composites of the overlapping period (Figure 5). In this result, no filtering for viewing conditions is then, ie. only selection of clear and good paired observations is performed. There appears to be a stronger consistency of the difference in the limited overlapping period, which starts to diverge for earlier and later observations. The Set2 results show that the effect of the additional offset correction is beneficial for the correspondence between PROBA-V and VGT2. Still, an important dispersion exists between the composites, which explains the poor statistical performance noted in section 5.4.

The GMslope regression is also derived for the NIR and Red products in each of the ten-daily composites, taking into account all clear and good paired observations, without any additional restrictions on observation geometry or illumination conditions. This is compared with a correction function for a processing issue found for VGT2 products, which is related to the sun-earth distance factor (VGT, 2014). A strong correlation is found (Figure 6), although the correction should be applied to the VGT2 top-of-atmosphere data to provide full confirmation.

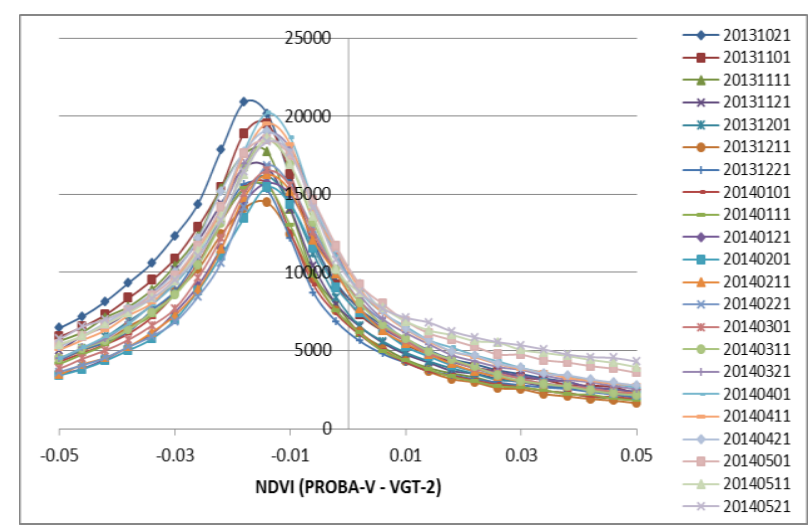

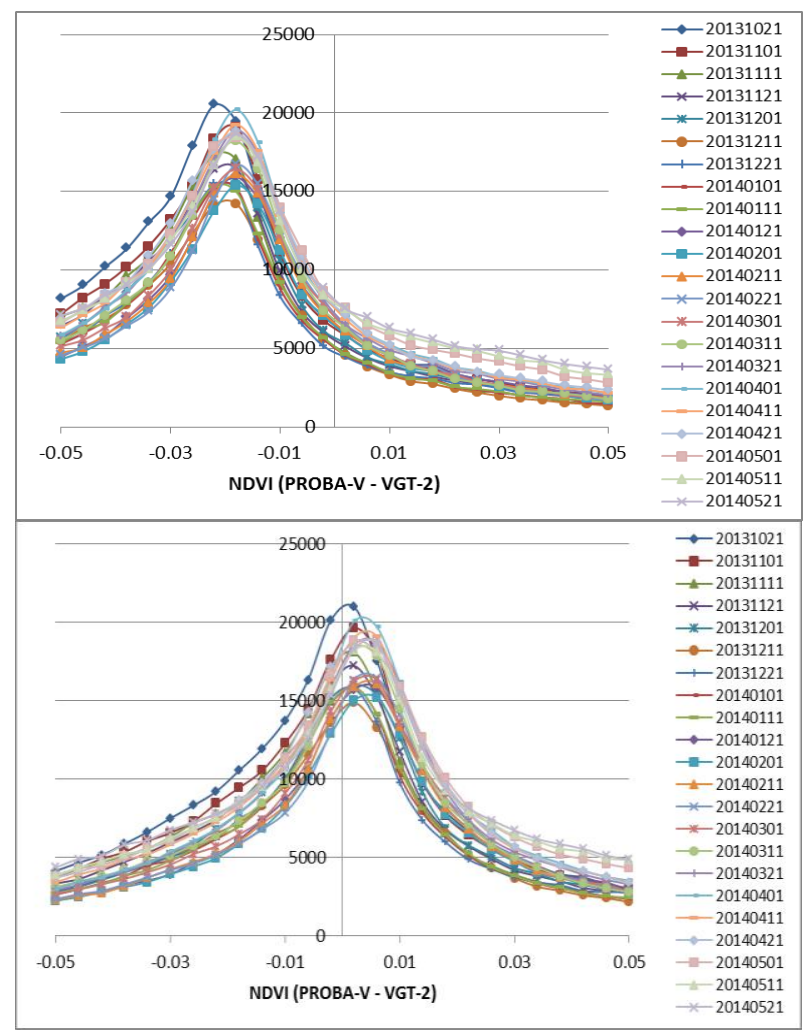

Figure 5. Histogram of the difference between the original (top), Set1 (middle) and Set2 (bottom) PROBA-V NDVI and VGT2 NDVI. Different curves are different composites

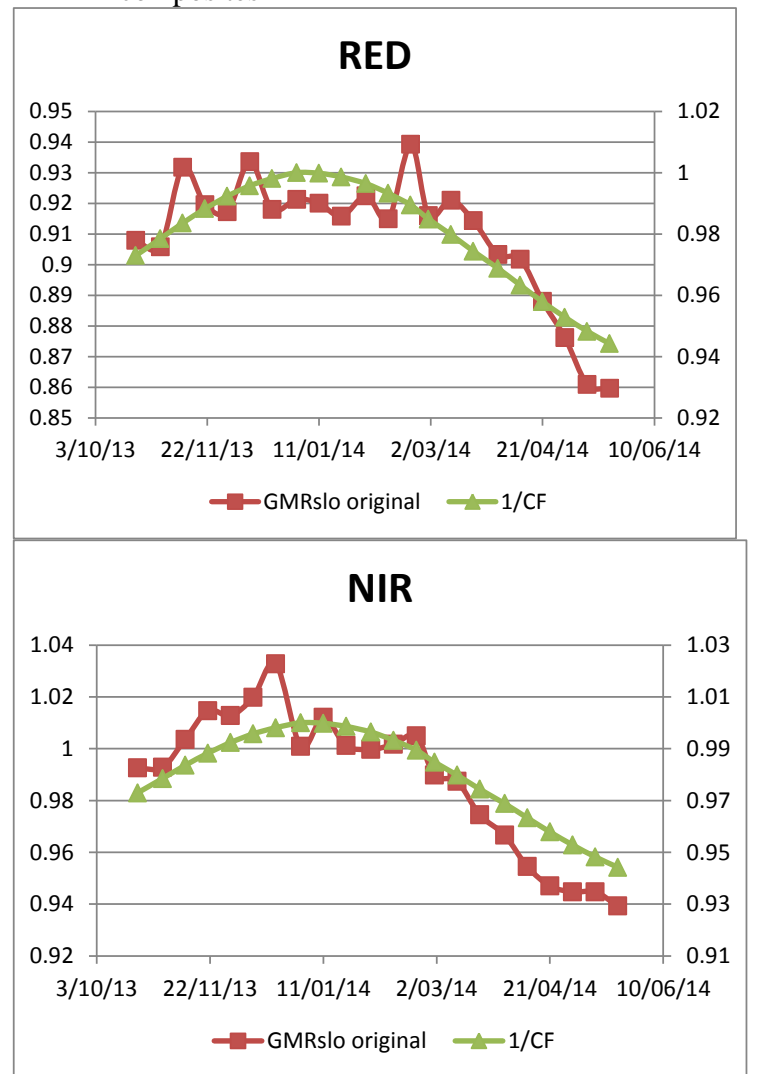

Figure 6. Slope of the GM regression line between PROBA-V and VGT2 RED (left) and NIR (right) reflectances for the overlapping period (left Y-axis), superimposed with the shape of the correction function for $\mathrm{d}^{2}$ (right $\mathrm{Y}$-axis). 


\section{DISCUSSION AND CONCLUSION}

The derivation of spectral correction functions between PROBA-V and SPOT-VEGETATION 2 has shown that the spectral consistency is initially very good. Almost 1:1 regression functions were established for Blue, Red, and NIR bands, showing only a noticeable change in the SWIR band (also known by design), and the derived NDVI product.

The application of the spectral correction function to the limited overlapping period in the first months of 2014 showed initially a good agreement, and led to the recommendation to apply an additional offset to the NDVI product. Similar offsets were not applied to the reflectance products, in order to preserve the relationship between reflectance value and its illumination conditions and observation geometry.

The final evaluation over the full overlapping period however showed a decrease in the correspondence between PROBA-V and VGT2, which was not improved by the spectral correction. A temporal trend in the correspondence between PROBA-V and VGT2 seems to be the root cause, as could be judged from the examination of differences between individual paired ten-day NDVI composites. The correspondence appears to be optimal in the first months of 2014, ie. the limited overlapping period.

Such temporal behavior can't be attributed to a difference in SRFs. A possible explanation could be the sun-earth distance issue in VGT2 data, but this has to be confirmed by future work.

\section{ACKNOWLEDGEMENTS}

The research that has led to these results has received funding from the Framework Programme (FP) of the European Community, and is operated through Copernicus, via GIO "Global Land Component of the GMES Initial operations".

\section{REFERENCES}

Bacour, C., Jacquemoud S., Tourbier Y., et al. 2002. Design and analysis of numerical experiments to compare four canopy reflectance models, Remote Sensing of Environment, 79(1), pp. 72-83.

Baret, F., O. Hagolle, B. Geiger, et al. 2007. LAI, fAPAR and fCover CYCLOPES global products derived from VEGETATION: Part 1: Principles of the algorithm. Remote Sensing of Environment, 110(3), pp.275-286.

Berk, A., et al. 2005. MODTRAN 5: a reformulated atmospheric band model with auxiliary species and practical multiple scattering options: update. In: Defense and Security. International Society for Optics and Photonics, pp. 662-667.

Dierckx, W., Sterckx, S., Benhadj I., et al. 2014. PROBA-V mission for global vegetation monitoring: standard products and image quality. Int. J. Remote Sens., 35(7), pp. 2589-2614.

Gonsamo, A., and J.M. Chen 2013. Spectral response function comparability among 21 satellite sensors for vegetation monitoring. IEEE Transactions on Geoscience and Remote Sensing, 51, pp. 1319-1335.

Jacquemoud, S., Verhoef, W., Baret, F., et al. 2009. Remote Sensing of Environment PROSPECT + SAIL models : A review of use for vegetation characterization. Remote Sensing of Environment, 113, S56-S66.

Saint, G. 1995. VEGETATION Onboard SPOT4: Mission Specifications - Version 3. Accessed March 25, 2014. www.vgt.vito.be/pages/VegetationSystem/mission.htm

Sterckx, S., Benhadj, I., Duhoux, G., et al. 2014. The PROBA$\mathrm{V}$ mission: Image Processing and Calibration. Int. J. Remote Sens., 35(7), pp. 2565-2588.

Steven, M. D., Malthus, T. J., Baret, F., et al. 2003. Intercalibration of vegetation indices from different sensor systems. Remote Sensing of Environment, 88(4), pp.412-422.

Trishchenko, A. P., Cihlar, J., Li, Z. 2002. Effects of spectral response function on surface reflectance and NDVI measured with moderate resolution satellite sensors. Remote Sensing of Environment, 81(1), pp. 1-18.

Thuillier, G., Hersé, M., Simon, P. C., et al. 2003. The solar spectral irradiance from 200 to $2400 \mathrm{~nm}$ as measured by the SOLSPEC spectrometer from the ATLAS 1-2-3 and EURECA missions, Solar Physics, 214(1), pp. 1-22.

VGT, 2014. Reflectance communication letter. Accessed on March 25, 2014.

http://www.vgt.vito.be/pdf/Reflectance_communication_letter_ V1.0.pdf.

Weiss, M., Baret, F., Eerens, H., et al. 2010. FAPAR over Europe for the past 29 years: A temporally consistent product derived from AVHRR and VEGETATION Sensors. In: Recent Advances in Quantitative Remote Sensing (RAQRS III), Valencia, Spain, pp. 428-433.

\section{APPENDIX: USED METRICS}

The GM model is of the form

$$
Y=a+b-X
$$

where

$$
\begin{aligned}
& b=\operatorname{sign}\left(\sigma_{X Y}\right) \frac{\sigma_{Y}}{\sigma_{X}} \\
& a=Y-b-\mu_{X}
\end{aligned}
$$

The statistical measures used are:

$$
\begin{aligned}
& M S D=\frac{1}{n} \sum_{i=1}^{n}\left(X_{i}-Y_{i}\right)^{2} \\
& M P D_{u}=\frac{1}{n} \sum_{i=1}^{n}\left(\left|X_{i}-\hat{X}_{\mathrm{i}}\right|\right)\left(\left|Y_{\mathrm{i}}-\hat{Y}_{\mathrm{i}}\right|\right) \\
& M P D_{g}=M S D-M P D_{u} \\
& M B E=\frac{1}{n} \sum_{i=1}^{n}\left(X_{i}-Y_{i}\right) \\
& A C=1-\frac{\sum_{\mathrm{i}=1}^{n}\left(X_{\mathrm{i}}-Y_{\mathrm{i}}\right)^{2}}{\sum_{\mathrm{i}=1}^{n}\left(|\bar{X}-\bar{Y}|+\left|X_{\mathrm{i}}-\bar{X}\right|\right)\left(|\bar{X}-\bar{Y}|+\left|Y_{\mathrm{i}}-\bar{Y}\right|\right)} \\
& \text { RMSE }=\sqrt{\frac{1}{n} \sum_{i=1}^{n}\left(X_{i}-Y_{i}\right)^{2}}
\end{aligned}
$$

